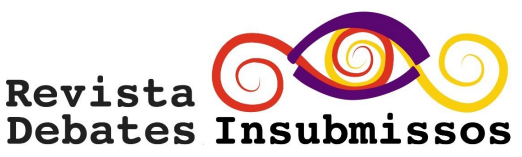

\title{
UM PASSEIO PELO SHOPPING CENTER EM BUSCA DE... GÊNERO E INFÂNCIA!!
}

\author{
A TOUR AT THE MALL IN SEARCH OF... \\ GENDER AND CHILDHOOD!!
}

Gabriela Silveira Meireles ${ }^{1}$

\section{RESUMO}

Este artigo foi produzido a partir de um ensaio fotográfico realizado para a disciplina Fotografia e Cultura Visual do Curso Mídias na Educação da Universidade Federal de Juiz de Fora no mês de dezembro de 2017. A proposta consistiu em registrar aspectos do gênero relacionado à infância em um shopping center, na cidade de Juiz de Fora. A princípio, o que comumente é uma atividade cotidiana, transformou-se em uma atividade de pesquisa. Assim, bastou sair do elevador e não tirei mais o dedo polegar do meu Iphone! Uma experiência inquietante, desconfortante, cheia de constatações importantes sobre como o nosso mundo é generificado e, mais ainda, como os produtos voltados para o consumo infantil também estão totalmente generificados! Para ampliar meu olhar, me embasei nos Estudos Culturais, para compreender que esses produtos também são capazes de educar as crianças, ou seja, que há uma pedagogia cultural no shopping center que ensina algo a essas crianças.

Palavras-Chave: Educação; Gênero; Infância; Estudos Culturais

\section{ABSTRACT}

This article is based on a photo-essay that was carried out for the Photography and Visual Culture discipline of the Media in Education course at the Federal University of Juiz de Fora in December 2017. The purpose was to register childhood-related gender aspects in a shopping mall in the city of Juiz de Fora. At first, what is commonly seen as an everyday activity turned into a research activity. The minute I stepped out of the elevator I could not take my fingers off my Iphone! An unsettling, uncomfortable experience full of important insights about how our world is genderized and, more importantly, how child-friendly products are also completely genderized! To broaden my view, I based myself on Cultural Studies to understand that these products are also capable of educating children, that is, there is cultural pedagogy in a mall that teaches these children something.

Keywords: Education; Gender; Childhood; Cultural Studies

\footnotetext{
${ }^{1}$ Doutora em Educação pela Universidade Federal de Minas Gerais (UFMG). Professora Adjunta do Curso de Psicologia da Faculdade Governador Ozanam Coelho (FAGOC). Coordenadora de Estágio no Centro de Pesquisas e Práticas em Psicologia Nise da Silveira, onde desenvolve Projetos de Extensão na área de Gênero e Sexualidade. E-mail: gabrielasilveirameireles@hotmail.com.
} 


\section{Revista}

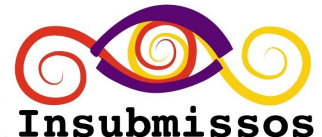

\section{INTRODUÇÃO}

Algumas vertentes dos estudos educacionais têm trabalhado com a abordagem dos Estudos Culturais no sentido de reafirmar a ideia de que as pedagogias, os currículos e os processos de ensino e de aprendizagem não estão mais restritos ao ambiente escolar. Autores/as desta abordagem têm reivindicado ainda que existe "pedagogia" nos mais diferentes artefatos como a mídia televisiva, as revistinhas em quadrinhos, os filmes (SABAT, 2001; FREITAS, 2008; GIROUX, 2012; PARAÍSO, 2004; 2007; SILVA, 2008). Tais artefatos ensinam "uma infinidade de práticas, comportamentos, sonhos e desejos que não podem ser desconhecidos pela educação" (PARAÍSO, 2004, p. 60).

Por isso, o espaço aqui analisado - o shopping center - passa a ser compreendido nesta perspectiva como um local de "produção de significados" (PARAÍSO, 2004, p. 60) e também de disputa por diferentes grupos culturais. É nesse espaço coletivo, em que circulam pessoas de estilos, pensamentos e modos de ser diversos, que começamos a ver delineados alguns grupos "nomeados e significados", que são: 1) Os grupos de produtos endereçados aos meninos e 2) Os grupos de produtos endereçados às meninas.

Ao tratar dos modos de endereçamento, Elizabeth Ellsworth (2001) nos incita a pensar no âmbito do cinema em um filme que idealizaria um tipo de indivíduo para o qual sua obra estaria indicada. Nesse caso, a própria autora reconhece que seria um pouco difícil às vezes acertar o alvo desse endereçamento, na medida em que "o espectador nunca é exatamente quem os produtores pensam que ele é - e tampouco quem ele próprio pensa que é". Todavia, em se tratando das questões de gênero e infância, percebemos que os modos de endereçamento são cada vez mais correlatos, óbvios e previsíveis, já que as divisões, demarcações e dicotomizações já estão previamente feitas não só nos espaços físicos (nos shoppings centers, por exemplo), como também na mente e no comportamento das pessoas.

Conforme já apontava Finco (2003) em suas pesquisas, meninos e meninas demonstram em suas brincadeiras, comportamentos, competências, atributos de personalidade mais apropriados para o seu gênero, seguindo desde bem pequenos essas normas e padrões estabelecidos. Essa autora complementa dizendo que as crianças aprendem o sexismo na 
escola já ao se defrontarem com mecanismos sutis de separação entre meninos e meninas para a realização de atividades e brincadeiras, por exemplo.

Busquei, portanto, perceber em que medida essas divisões de gênero estavam sendo perpetuadas, mantidas, divulgadas e consumidas. Para isso, resolvi fazer um passeio (confesso que, de início, sem um roteiro prévio) pelo shopping, localizado na região mais periférica da cidade de Juiz de Fora, mas frequentado tanto pela classe popular quanto pela classe média. A seguir, analisarei cada etapa da minha visita, que se deu por setores ou tipos de itens vendidos, a saber: 1. Vestuário; 2. Brinquedos; 3. Diversão/Lazer; 4. Guloseimas; 5. Cosméticos; 6. Material Escolar.

\section{SETOR 1: VESTUÁRIO}

Quando partimos do princípio de que meninos e meninas devem vestir roupas (e também sapatos e outros adereços) diferentes, estamos reafirmando uma diferença que não é biológica ou natural (o que estaria se referindo ao sexo), mas sim a uma questão de gênero, que é construída social e culturalmente e envolve "um conjunto de processos que vão marcando os corpos, a partir daquilo que se identifica ser masculino e/ou feminino" (GOELLNER, 2012, p. 109). Por ser uma construção histórica e social, é possível dizer que o que é considerado feminino hoje, já foi considerado masculino há algum tempo atrás ou em outro contexto social e vice-versa.

Nessa perspectiva, fica mais fácil problematizar que o azul seja considerado "cor exclusiva" de roupa para os meninos e o rosa "cor exclusiva" de roupa para as meninas, como veremos em algumas das fotografias a seguir. Do mesmo modo, as personagens e seus padrões de comportamento e vestimenta somente são consideradas exclusivas para meninos ou meninas porque nos levam a acreditar que é "natural" que meninas gostem de princesas e bonecas fofas, enquanto meninos gostem de super-heróis e carros. Essas definições e divisões foram construídas e podem também ser desconstruídas e reconstruídas. Isso vale para as próprias vestimentas das crianças: Quem definiu que meninas devem usar saias e vestidos e meninos devem usar shorts e calças? Há lugares e culturas, por exemplo, em que os homens 
usam saias ou vestidos ${ }^{2}$. O uso de calças pelas mulheres também nem sempre foi comum. Pode-se dizer que foi uma conquista do Movimento Feminista ${ }^{3}$. Essas são construções de época e contexto sócio-histórico. Diante de tanta polêmica em relação à vestimenta dos/as seus/suas alunos/as, o Colégio Pedro II, no Rio de Janeiro, chegou a liberar o uso de short e saia para todos/as, independente do gênero ${ }^{4}$, o que mostra que esse é um "território em permanente disputa" (FOUCAULT, 2005).

Ao observar as imagens desse setor, notamos primeiro que há uma divisão espacial há uma arara (ou cabide) para as roupas das meninas e, ao lado (ou embaixo), outra arara (ou cabide) para as roupas dos meninos. Parece banal, corriqueiro, mas essa divisão já nos obriga a direcionarmos nossa compra para um ou outro gênero, o que torna o nosso olhar binário e dicotômico. Quantas e quantas vezes já não cheguei em uma loja, em um departamento infantil, e a vendedora (sempre mulher) me vinha sempre com a primeira pergunta, após os cumprimentos: "É menina ou menino?”. E eu sempre dizia: “Tanto faz...” ou "Não importa..." ou "Não sei ainda...". E lá vinha uma cara de espanto e a resposta: "Como assim?” ou "Ah, então não dá pra escolher!" ou “Como vamos fazer então?”.

Se olharmos atentamente para as imagens, entenderemos esse espanto ou o fato de essas vendedoras ficarem perdidas... As vestimentas infantis estão seriamente demarcadas pela cor (azul ou rosa) e também pelas personagens dos desenhos animados e filmes infantis. E o que é mais sério: Aquelas personagens que agradam os meninos (Batman, Homem Aranha, Capitão América, Carros, Ben 10, Mc Queen, etc), as meninas detestam! E aquelas personagens que agradam as meninas (Princesas, Super Poderosas, Hello Kit, Barbie, A Marsha e o Urso, Frozen, etc) causam irque nos meninos!

\footnotetext{
${ }^{2} \mathrm{Na}$ Escócia, a saia é uma vestimenta usada por homens em situações formais, como casamentos, formaturas, comemorações e eventos especiais, esportivos e tradicionais. Era também usada como uniforme pelos exércitos escoceses até a Primeira Guerra Mundial. Ver mais em: < https://www.brasileiraspelomundo.com/os-homensusam-saia-na-escocia-151939867>. Acesso em: 29 mar. 2018.

3 Ver mais em: http://www.todasfridas.com.br/2017/01/29/a-primeira-vez-em-que-mulheres-usaram-calcas/. Acesso em: 29 mar. 2018.

${ }^{4}$ Ver mais em: < https://extra.globo.com/noticias/rio/colegio-pedro-ii-no-rio-libera-saia-para-meninos-short-parameninas-20144252.html > Acesso em: 29 mar. 2018.
} 

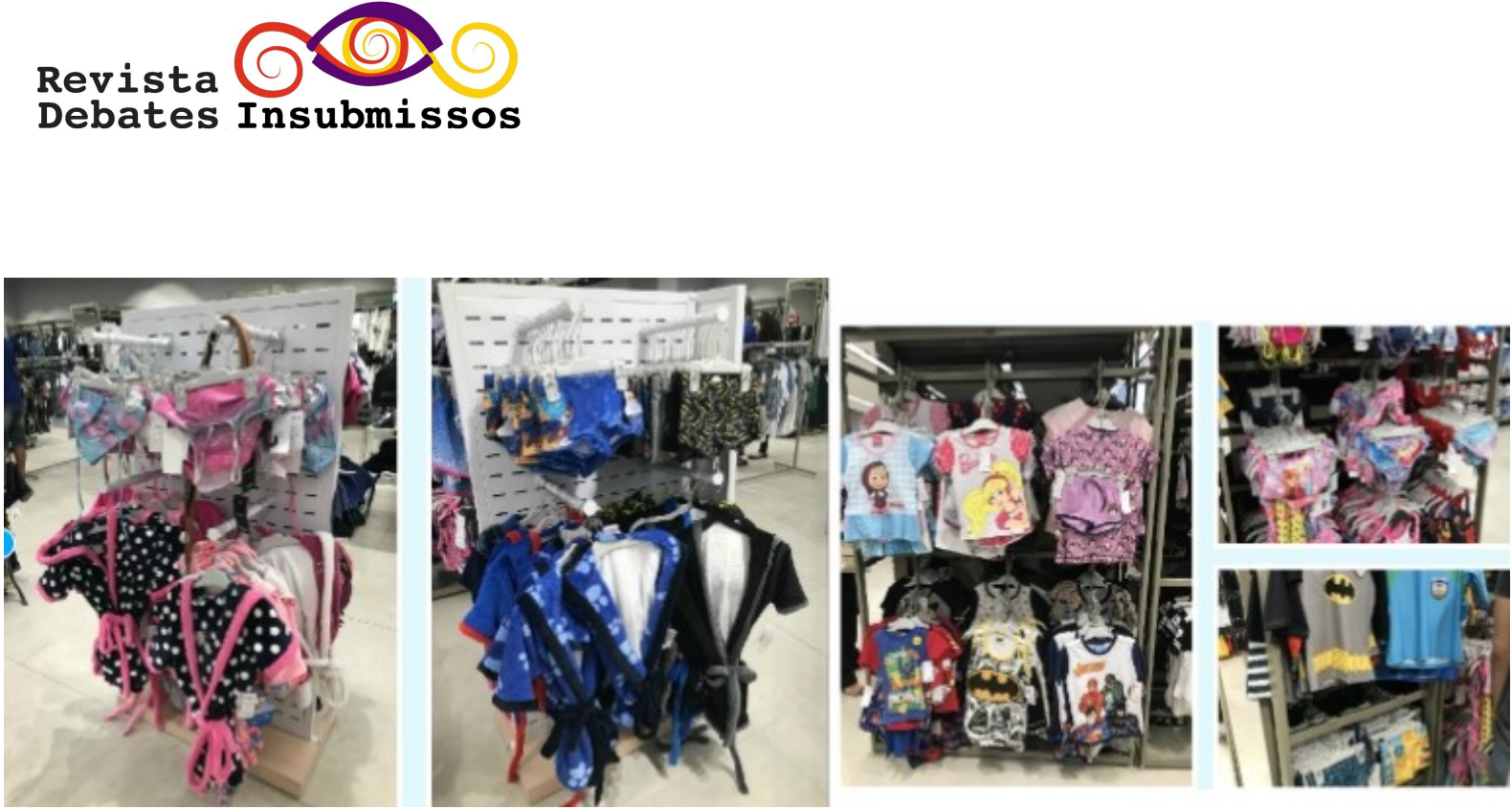

Fonte: Ensaio fotográfico realizado pela autora do artigo

Ainda mais sério é quando estas demarcações na vestimenta passam a servir como critério de julgamento da sexualidade dessas crianças. Caso não se enquadrem nesses estereótipos de gênero, ou seja, caso alguma menina goste das roupas consideradas de menino ou algum menino goste das roupas consideradas de menina, passa-se a colocar em questão a sua feminilidade ou a sua masculinidade, o que gera o pensamento de que ela "deve ser homossexual" (GOELLNER, 2012, p. 112). Ou mesmo que não seja considerada gay ou lésbica agora, começa a ser alimentado o medo ou receio de que aquela criança se torne um/uma homossexual no futuro. Isso em função da rigidez do que lhes é oferecido em termos de vestimenta.

\section{SETOR 2: BRINQUEDOS}

A maior e mais conhecida loja de brinquedos atualmente no Brasil (e também a mais desejada pelas crianças de classe média/média alta), disponibiliza em seu repertório os brinquedos mais "clássicos" para meninos e meninas: para eles, muitas prateleiras de carrinhos de todos os tipos, cores e tamanhos; para elas, muitas Barbies (em sua maioria cor de rosa ou lilás) e várias bonecas de colo (a vencedora é a baby alive, que custa em média $\mathrm{R} \$ 200,00$ ). Além disso, é curioso notar que há alguns brinquedos iguais (para meninos e meninas), mas que o mercado faz questão de produzir em um formato, marca ou cor diferente para meninos e meninas. Por que será? Porque eles acreditam que um jogo do Cara-a-Cara rosa e das princesas atrai mais uma menina do que um Cara-a-Cara branco e vermelho sem 
nenhuma personagem. E também porque eles acreditam que meninas preferem a Minnie, enquanto meninos preferem o Mikey. E também porque eles insistem para que essa preferência exista para que eles criem novos produtos diferenciados e vendam mais... vendam mais, vendam mais!!!
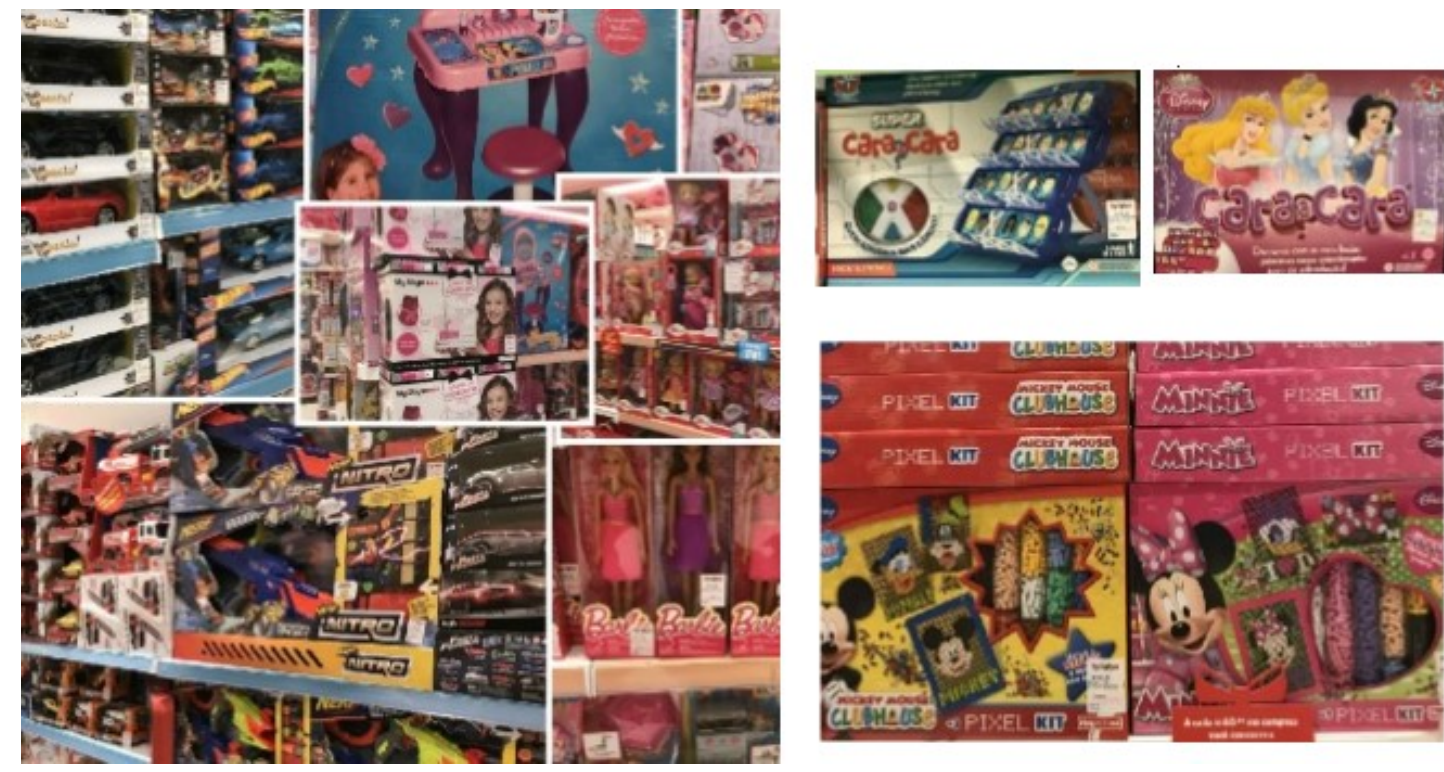

Fonte: Ensaio fotográfico realizado pela autora do artigo

O mercado do consumo quer esse sujeito diferenciado, essa criança que vai até a loja e compre algo que seja do "seu perfil". Os grandes donos de lojas e redes de lojas querem que essa divisão se mantenha, porque assim aumentam seus lucros. Daí a importância de problematizarmos a concepção de infância como aquela pautada apenas nos "aspectos motores, cognitivos e afetivos do desenvolvimento" (FELIPE; GUIZZO, 2003, p. 120). É preciso discuti-la como o produto de conjunto de discursos e efeitos de verdade que envolvem as construções de gênero e o governo de seus corpos.

Nessa direção, é preciso estarmos atentos/as ao potencial consumidor que essas crianças vêm assumindo nos últimos anos. Como mostram Felipe e Guizzo (2003), elas têm sido um alvo interessado das publicidades, tanto na televisão, quanto na internet (YouTube, Facebook, Instagram, Blogs, Vlogs, etc), sendo ao mesmo tempo vista como consumidoras e objetos a serem consumidos. Os shoppings centers são um desses espaços "planejados de modo a contemplar esse segmento da população" (FELIPE; GUIZZO, 2003, p. 120). 
No shopping center onde realizei o ensaio fotográfico, pude notar que os brinquedos ainda se encontram bastante divididos, inclusive em corredores distintos da loja, em prateleiras diferentes e, em alguns casos, o atendimento é feito, inclusive, por vendedoras diferentes, já que cada uma fica responsável por um desses corredores (ainda mais em época de fim de ano, em que as lojas ficam muito cheias). Diante de tais separações, fica até difícil para a criança encontrar algo que "escape" a essas normas de gênero. A hipótese levantada por Finco (2003) é a de que não são as crianças que apresentam práticas ou escolhas sexistas em relação às suas brincadeiras, mas que estas são construções e reproduções do mundo adulto.

Para desconstruir isso, é necessário questionar conceitos pré-concebidos e atribuir novos significados à nossa história, de modo a enxergar as múltiplas formas de ser menino e de ser menina, de brincar e fazer uso dos mais diversos brinquedos, permitindo que sejam eles/as mesmos/as e vivam a infância intensamente (FINCO, 2003), sem medos, sem demarcações, sem proibições em função do gênero ou outra característica.

\section{SETOR 3: DIVERSÃO E LAZER}

Do infantil ao tecnológico em segundos!!! Andando pelo shopping center visitado, em Juiz de Fora, revisitei a minha infância da década de 1980, com esses balões de gás, em que andávamos orgulhosos/as pela rua, satisfeitos com aquela "aquisição". Na época também haviam personagens e divisão de cores (e não eram muito diferentes: Barbies, Princesas, às vezes flores, cachorrinhos, gatinhos, etc). Para meninos, não me lembro... Afinal, eu era menina! E os mundos já não se cruzavam... Hoje, surgiram novas personagens, outras se mantiveram. Mas a divisão de cores é praticamente a mesma: o azul para meninos e o rosa para meninas. É claro que existe uma paleta de cores permitida para os meninos além do azul (verde e amarelo, por exemplo) e outra para as meninas além do rosa (lilás e vermelho, por exemplo). O vermelho ainda é mais neutro! E as meninas ainda podem usar mais livremente o verde e o amarelo, mas quase nunca são suas cores favoritas. Já o lilás quase nunca é permitido para os meninos! Há, sim, uma grande “disputa” em torno das cores! 
E essa disputa se mantém quando se trata das "novas" tecnologias. Os DVDs (Capas dos Filmes) destinados aos meninos são predominantemente azuis e aqueles destinados às meninas quase em sua totalidade rosa. $\mathrm{O}$ mesmo ocorre com os Tablets (alvo preferido da criançada!). Quando não vêm de fábrica já azul ou rosa, existem capinhas próprias nessas duas cores (e geralmente apenas nessas duas!).
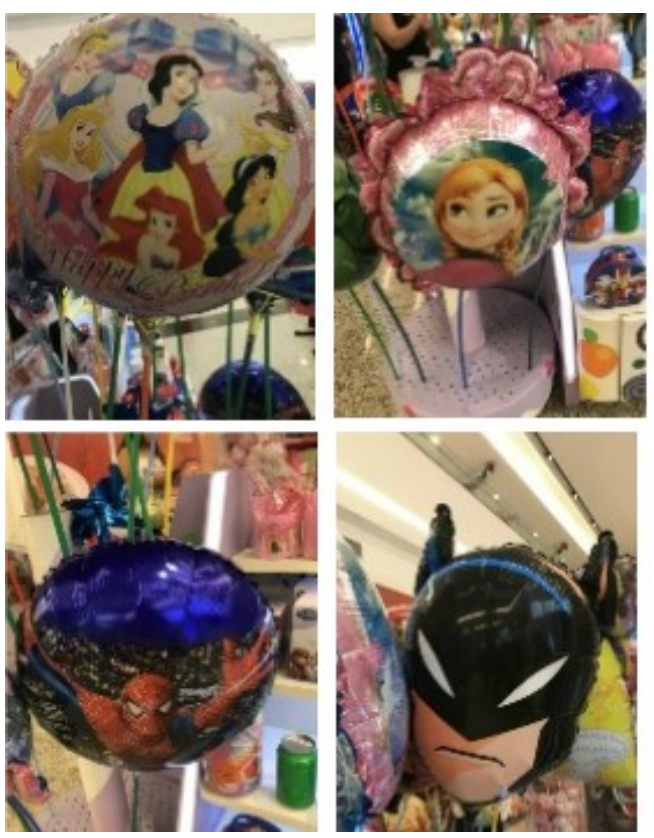
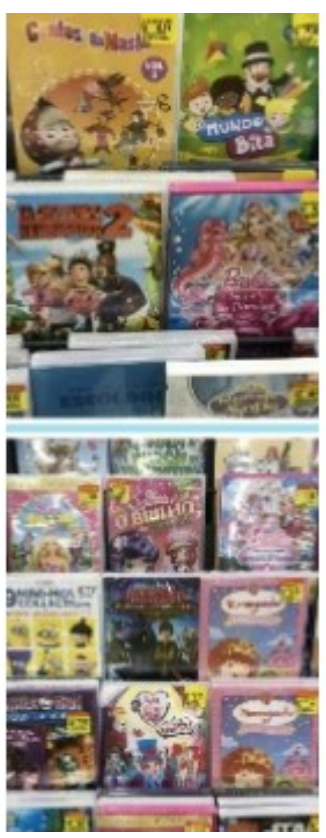

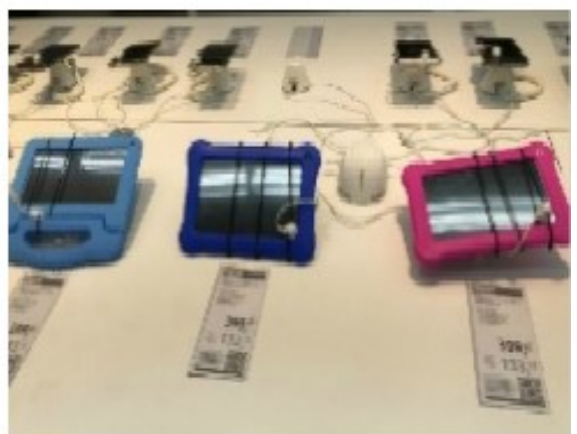

Fonte: Ensaio fotográfico realizado pela autora do artigo

Nossas crianças habitam um mundo híbrido. Um mundo em que convivem as antigas e as novas brincadeiras, os antigos e os novos equipamentos e máquinas, as velhas e as novas tecnologias. Michel Serres (2013) as denominou de Polegarzinhas, porque elas lidam o tempo todo com as mestiçagens humanas, com as misturas de saberes e de culturas. Elas têm em relação a nós um diferencial: elas manipulam várias informações ao mesmo tempo, elas habitam o virtual, elas têm acesso a todas as pessoas, a todos os lugares, elas circulam, elas organizam o pensamento e as informações de um modo diferente. Essas crianças não precisam mais ir à escola para ter acesso à informação, como algumas gerações passadas. As informações estão disponíveis em todo lugar, no toque de suas mãos, na tela da TV, do Tablet, do Notebook. A isso Serres (2013, p. 19) chamou de "sociedade pedagógica", uma 
sociedade em que "a mídia assumiu a função do ensino". Se isso faz diminuir a credibilidade da escola? O autor afirma que não, pois a nossa sociedade ainda é uma sociedade pautada no "saber" e, portanto, “a confiança no saber e na formação" estão, em sua opinião, crescendo (SERRES, 2000).

\section{SETOR 4: GULOSEIMAS}

É para comer, mas tem cor (rosa ou lilás) e cara de personagens (Frozen, Carros, Minions, Super Poderosas, Princesas e Monstros). O suco é da mesma marca e provavelmente tem o mesmo gosto, mas um é para as meninas (com a Elza e o Olaf) e o outro é para os meninos (com o Mc Queen). Com os marshmallows, a divisão é por cor; a marca é a mesma e o gosto também, mas um é rosa (para as meninas) e o outro é azul (para os meninos). Já as balas Fini (sucesso total entre as crianças!), prefere separar por personagens (os Minions para os meninos e as Super Poderosas para as meninas). Quanto ao Kinder Ovo, a discussão é antiga e mobilizou comentários de vários sites desde 2013, quando foram lançados divididos por cores e rotulados como sendo para "meninas" e para "meninos".

A empresa chegou a lançar um chocolate Kinder Ovo verde, intitulado "Natoons" e com um tema de Animais da Natureza, que pareceu, na época tentar criar algo "neutro" para abafar as discussões, mas que acabou não funcionando... Porque não vendeu e acabou reforçando a dicotomia já existente entre meninos e meninas. Até porque o verde e o tema “animais" é considerado de menino e não de menina.

\footnotetext{
${ }^{5}$ Ver mais em: https://epocanegocios.globo.com/Informacao/Acao/noticia/2013/03/kinder-ovo-cria-ovo-diferentepara-meninos-e-meninas-e-e-chamado-de-sexista.html; https://www.em.com.br/app/noticia/economia/2013/03/13/internas economia,356657/kinder-ovo-lanca-ovos-parameninos-e-meninas-e-marca-e-chamada-de-sexista.shtml; http://g1.globo.com/economia/midia-emarketing/noticia/2013/03/apos-ser-chamado-de-sexista-kinder-ovo-diz-respeitar-diferentes-opinioes.html. Acesso em: 29 mar. 2018.
} 


\section{Revista $0(0)$ \\ Debates Insubmissos}
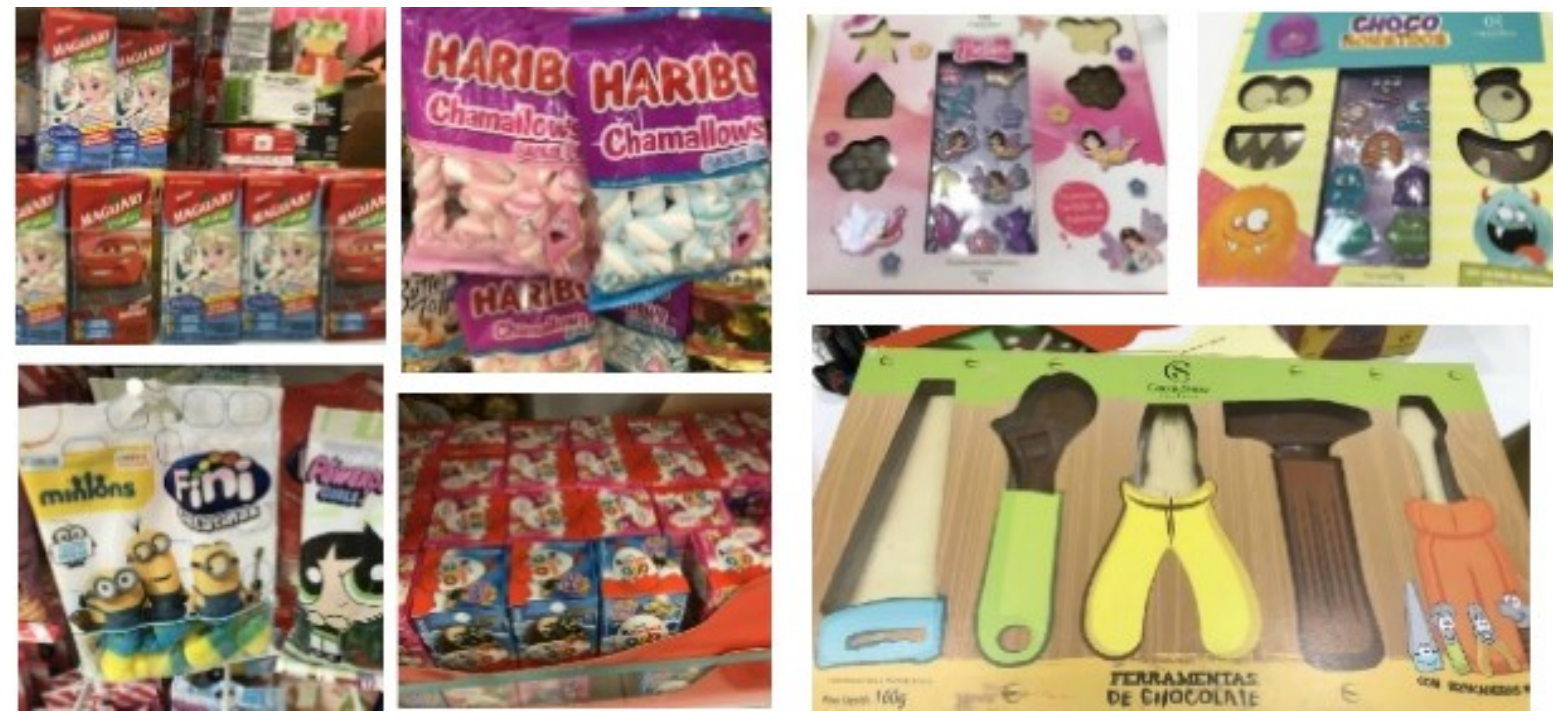

Fonte: Ensaio fotográfico realizado pela autora do artigo
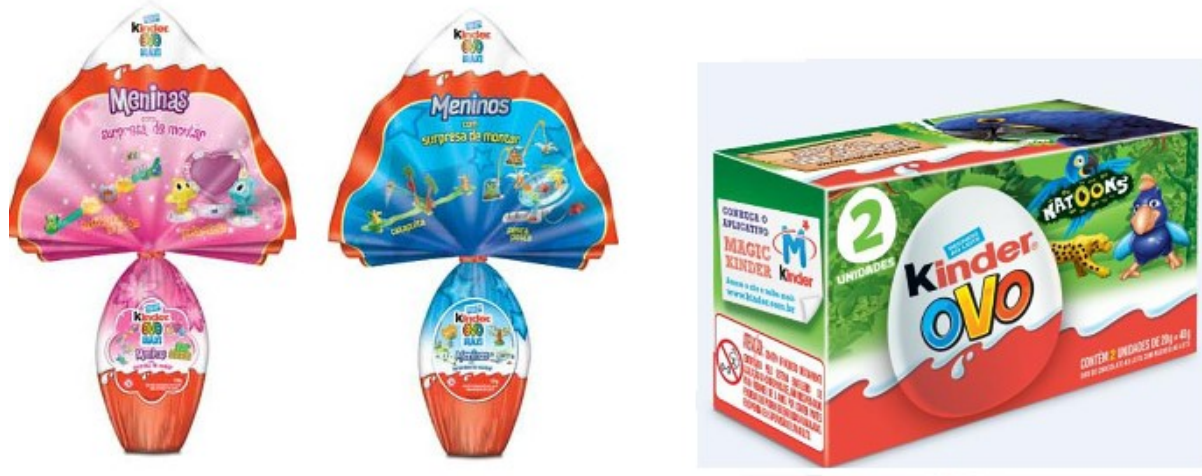

Fonte: https://epocanegocios.globo.com/Informacao/Acao/noticia/2013/03/kinder-ovo-cria-ovo-diferente-parameninos-e-meninas-e-e-chamado-de-sexista.html e http://www.clubedaembalagem.com.br/noticias/kindernatoons-apoia-causa-da-arara-azul/

Outro choque foi entrar em uma das lojas mais badaladas do momento no setor de Guloseimas no Brasil e encontrar, primeiro, para minha surpresa, uma prateleira destinada às crianças (algo relativamente recente, já que essa loja inicialmente priorizava um público mais adulto). Depois, a surpresa ao encontrar não só a separação de cores ou personagens (comum em todos os outros setores já analisados aqui neste artigo, mas também de funções e também de sonhos ou um mundo de imaginação. Ao perguntar à vendedora o que ela teria a me oferecer para crianças, ela disse: "Para os meninos tenho esse kit de ferramentas e esse dos 
monstrinhos"; "Para as meninas, tenho esse das fadinhas...". A ferramenta é algo que, na vida real somente é permitido aos homens mexer, pois as únicas funções no âmbito do lar/do privado que são destinadas aos homens são aquelas consideradas "pesadas" para as mulheres ou aquelas para as quais elas são consideradas "inaptas" a realizar (Exemplo: Capinar o jardim, Limpar a piscina, Trocar uma lâmpada, Trocar o chuveiro, Desligar a chave geral de energia, Desentupir a pia, etc). E um presente desses, ainda que de comer, já pode ir servindo de "inspiração" para os meninos assumirem tais funções.

Já quando se trata do mundo da fantasia e da imaginação, também há uma demarcação para os meninos e as meninas. Eles devem imaginar coisas mirabolantes, criativas, sombrias, grandes castelos com reis mandões, ladrões, exércitos e monstros. Elas devem imaginar coisas delicadas, doces, um castelo lindo, no alto de uma montanha com nuvens brancas, uma linda princesa com um vestido longo ou então fadas voadoras e encantadas que realizam desejos de meninas sonhadoras e românticas. Ou seja, nem tudo é permitido ao menino e à menina sonhar. Até os sonhos são controlados e governados pelo gênero!

\section{SETOR 5: COSMÉTICOS}

Os produtos de cuidado e higiene pessoal também são alvo dos investimentos de gênero. Desde a mais tenra idade, quando ainda são bebês e ainda não escolhem que produtos são necessários para sua higiene e limpeza, os pais, as mães, os/as avós ou outro/a cuidador das crianças fazem por ela tais escolhas. Ao chegar em uma loja de departamento, mercado ou farmácia, essa pessoa já encontrará produtos para cada finalidade específica (higiene local na troca de fraldas, higiene corporal, higiene dental, etc). Para a troca de fraldas, há lenços humedecidos azuis de meninos e rosa de meninas. Para a higiene pessoal, há shampoos da marca Tralalá (azul de menino e rosa de menina); Johnson`s (em três cores: azul - cheirinho prolongado; rosa - gotas de brilho; e verde - cabelos claros), que, a princípio, não parecem ter relação com os gêneros, mas, do modo como estão dispostos, o azul e o rosa em cima e o verde embaixo, sugerem que o azul seja para meninos e o rosa para meninas; há também o do HotWells e o da Barbie, que dividem claramente, pelo formato de caixa, pelas cores e personagem, que um é para meninos e o outro para meninas. Diante disso, faz-se urgente 
buscarmos nos afastar de tais "posições essencialistas sobre os gêneros" e pensar os gêneros "de modo plural", "não binária", incluindo diferentes formas de masculinidade e feminilidade para aquelas crianças que porventura não se enquadrem "em uma dessas formas" (azul ou rosa, princesa ou monstro)... (LOURO, 1997, p. 34). O problema é que isso pode "abalar as estruturas", os pensamentos rígidos...
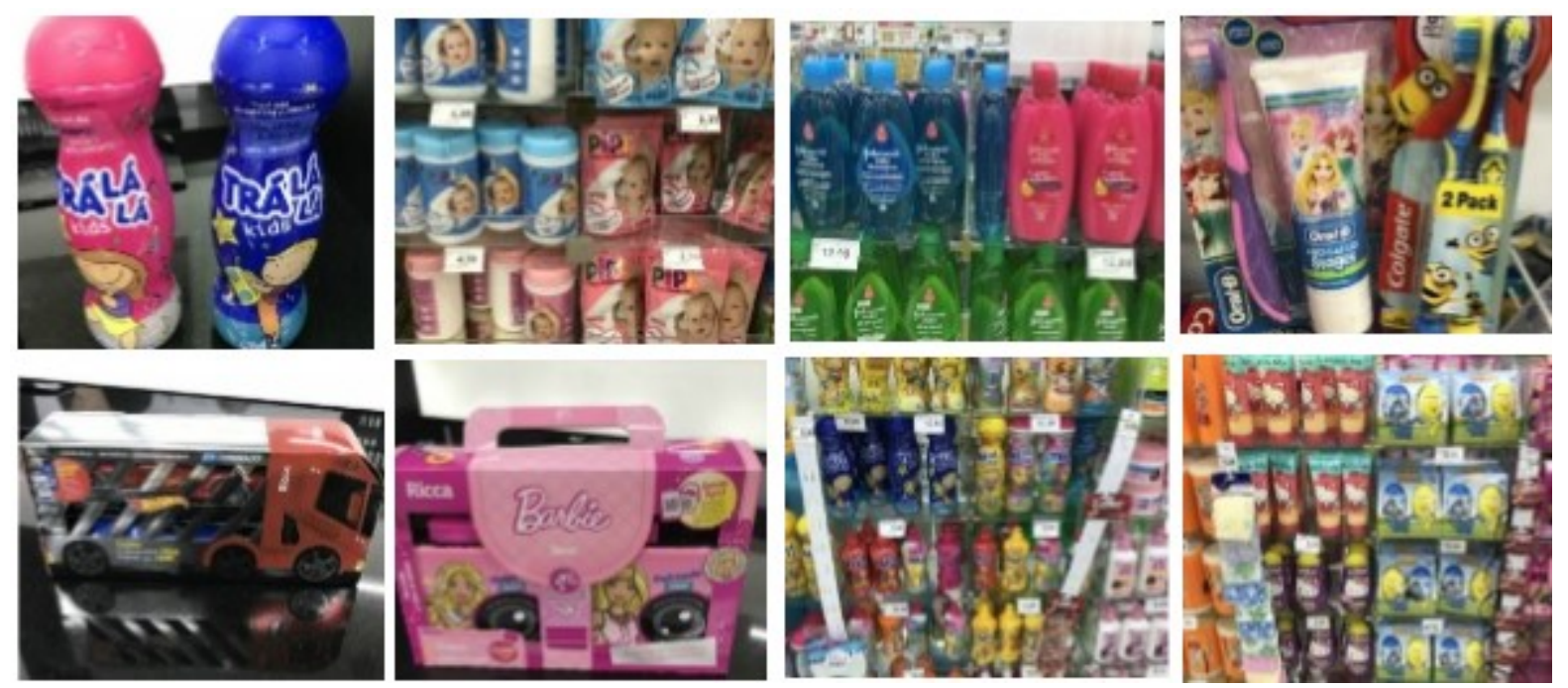

Fonte: Ensaio fotográfico realizado pela autora do artigo

O consumo desse tipo de produto pelas crianças, ainda que adquiridos indiretamente por seus pais, suas mães ou seus/suas cuidadores/as, reforça uma visão de saúde predominante na década de 1980, que "depende, unicamente, dos hábitos de higiene de cada criança" (LEAL, 1998, p. 73), desconsiderando as condições sociais e econômicas em que vivem e também as condições de adquirirem tais produtos, que não são nem um pouco "baratos" (Exemplo: R\$22,99 o shampoo da Barbie e R \$29,99 o shampoo do HotWells). Há, ainda, algo da ordem do "embelezamento" que extrapola a dimensão da saúde e que se faz presente apenas nos produtos direcionados às meninas. Para os meninos, são oferecidos o shampoo e o condicionador da Galinha Pintadinha em azul e amarelo. Para as meninas, o shampoo da Hello Kit e o "Creme para Pentear" (utilizado no universo adulto, para tornar o cabelo das mulheres mais lisos, padrão este considerado ideal e belo para os cabelos femininos). Nesse caso, a saúde e a higiene deixam de ser preocupação dos/as vendedores/as dos cosméticos infantis, tornando o alcance dos padrões de beleza alvo de seus interesses também. Nesse 
processo, o "embelezamento feminino" torna-se um "dever" de toda menina, um modo de ela demonstrar domínio da sua natureza corporal (SANT'ANNA, 2003).

\section{SETOR 6: MATERIAL ESCOLAR}

Quando pensamos nas crianças, é natural que imaginemos que os materiais escolares são os itens mais apropriados para o consumo nessa faixa etária. Muitas mães, pais, tios, tias, madrinhas, padrinhos, avós, avôs e outras pessoas que convivem com esses sujeitos infantis gostam e costumam incentivar bastante o consumo desse tipo de material, principalmente no início (quando a criança vai pela primeira vez à escola) ou no recomeço das aulas. Geralmente, as listas de materiais escolares são repletas de itens e exigem também um alto investimento financeiro dos pais e/ou responsáveis pelas crianças (o que nem sempre corresponde à situação financeira real deles). Algumas listas chegam a ser abusivas ${ }^{6}$, mas, ainda assim, muitos pais chegam a se endividar para agradar os/as filhos/as.

Algumas vezes as exigências passam, inclusive, na escolha dos materiais em função das personagens de desenhos e filmes mais famosos no momento, o que inclui a estampa deles em mochilas, lancheiras, sombrinhas, guarda-chuvas e cadernos. Nesse caso, quanto mais famoso/a é o/a personagem, mais caro é o produto (Exemplo: Uma mochila do Frozen hoje pode custar $\mathrm{R} \$ 201,43^{7}$; já uma mochila das Princesas custa hoje $86,99^{8}$ ). Antes do lançamento do filme Frozen, uma mochila das Princesas talvez custasse mais caro do que qualquer outra na preferência das meninas. O mesmo ocorre entre os meninos, onde a

\footnotetext{
${ }^{6}$ Ver mais em: http://www.correiobraziliense.com.br/app/noticia/euestudante/ensino educacaobasica/2018/01/11/ensino educacaobasica interna,652601/o-que-as-escolas-podempedir-na-lista-de-material-escolar.shtml. Acesso em: 29 mar. 2018.

${ }^{7}$ Ver em: https://www.google.com.br/search?q=mochila + do + frozen\&source=lnms\&tbm=shop\&sa $=$ X\&ved=0ahUKEwi4gs2 91JTaAhXKPpAKHbHTCr0Q_AUICigB\&biw=1366\&bih=662. Acesso em: 29 mar. 2018.

${ }^{8}$ Ver em: https://www.google.com.br/search?q=mochilas+infantis\&hl=pt-

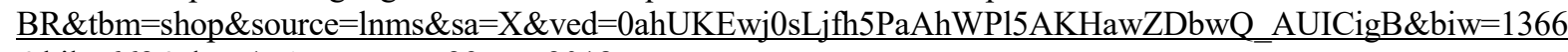
$\underline{\& b i h=662 \& d p r=1}$. Acesso em: 29 ma. 2018.
} 


\section{Revista}

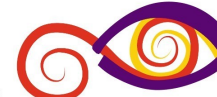

Debates Insubmissos

preferência era o Ben-10 (encontra-se mochilas desse personagem por R $\$ 89,99^{9}$ ) e agora é o Carros/Mc Queen (algumas mochilas desse personagem chegam a custar R $\$ 247,54^{10}$ ).

As cores também são quesitos importantes, tanto para demonstrar que aquele produto é fiel ao/à personagem principal do desenho animado ou do filme ali representado quanto para demarcar a que gênero pertence aquele produto. Assim, algumas cores são usadas para as personagens dos desenhos e filmes indicados para meninos: azul, verde, preto e vermelho; e outras cores são usadas para as personagens dos desenhos e filmes indicados para meninas: rosa, lilás e o azul (com exceção para o filme Frozen, mas com o detalhe das alças em lilás, para demarcar que é para meninas).
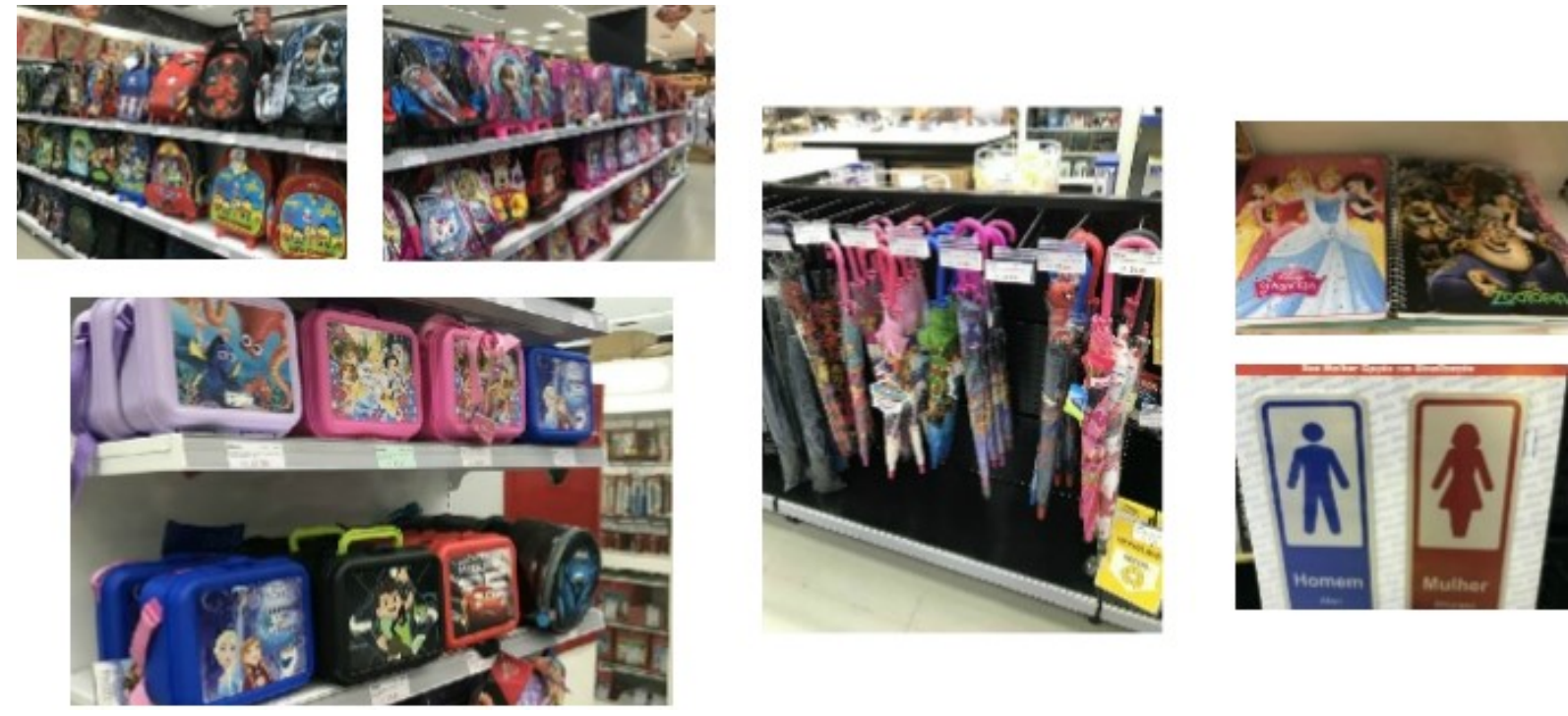

Fonte: Ensaio fotográfico realizado pela autora do artigo

A escola, enquanto instituição histórica, tem também essa marca da separação dos sujeitos (LOURO, 1997). Não apenas em função da cor de seus pertences, mas, em sua

\footnotetext{
${ }^{9}$ Ver em:

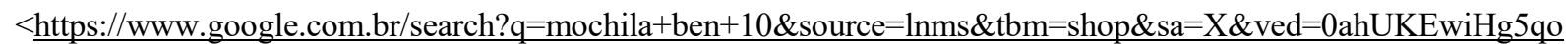
iZPaAhWDEZAKHesgBRsQ AUICigB\&biw=1366\&bih=662>. Acesso em: 29 mar. 2018.

${ }^{10}$ Ver em: https://www.google.com.br/search?hl=ptBR\&biw=1366\&bih=662\&tbm=shop\&ei=A6m9WvfKG4aLwgSQ2JzoAw\&q =mochila + carros\&oq=mochila + carr os\&gs l=psy-ab.3..0110.270749.273641.0.273789.11.10.0.0.0.0.245.964.0j2j3.5.0...0...1c.1.64.psyab..6.5.963....0. A-SoPmkAc8\#spd=0. Acesso em: 29 mar. 2018.
} 
própria origem, em a partir daqueles que nela entravam e dos que a ela não tinham acesso. Desde então ela passou a demarcar espaços distintos, a instituir também "o 'lugar' dos pequenos e dos grandes, dos meninos e das meninas" (LOURO, 1997, p. 58). Contudo, por ser também a escola um espaço sempre aberto de relações entre sujeitos infantis diversos, vale destacar que frequentemente as próprias crianças "subvertem o senso comum de 'lados opostos' entre meninos e meninas" (LOURO, 1997, p. 79), uma vez que nela também são possíveis os agrupamentos mistos (pátios, corredores, parquinhos e, às vezes, até mesmo as salas de aula). Ainda que existam as demarcações rígidas (como as plaquinhas de banheiro), a escola é esse espaço em que também é possível o “cruzamento de fronteiras”!

\section{MAIS ALGUNS CLICS...}

A experiência de passear pelo shopping center na cidade de Juiz de Fora, um local comum e de lazer para mim, habitando-o como pesquisadora interessada que fui, em busca de compreender uma infância generificada que estava sendo produzida a partir de diversos artefatos culturais (imagens, desenhos animados, filmes infantis, personagens, etc), foi muito prazerosa!

Deparar-me com a diversidade de setores e produtos destinados ao público infantis foi para mim uma surpresa e, ao mesmo tempo algo que eu já sabia que iria encontrar. Surpresa porque eu não imaginava que as crianças estavam tão "cercadas" por todos os lados e tão controladas pela publicidade e pelas agências de mercado, distribuídas em produtos de variados tipos e setores. Mas, ao mesmo tempo, algo já esperado por saber que o público infantil vem ganhando cada vez mais espaço de consumo e, portanto, mais prateleiras nos shoppings centers.

A produção generificada da infância em todos os tipos de artigos, produtos e setores de forma massiva e padronizada (em cores e personagens) foi realmente algo assustador e soou como uma sirene em meus ouvidos, solicitando-me que gritasse: "Por favor, faça alguma coisa para que as crianças saiam dessa rede binária! Permita-lhes ser outra coisa diferente disso que lhes é apresentado!”. Até que um sopro me veio no canto do ouvido: "Deixe que as 
próprias crianças dêem o seu jeito. O jeito delas é melhor que o nosso. Fomos nós que fizemos isso com elas...".

\section{REFERÊNCIAS}

ELLSWORTH, Elizabeth. Modo de endereçamento: uma coisa de cinema; uma coisa de educação também. In: SILVA, Tomaz Tadeu da (Org.). Nunca fomos humanos: nos rastros do sujeito. Belo Horizonte: Autêntica, 2001.

FELIPE, Jane; GUIZZO, Bianca Salazar. Erotização dos corpos infantis na sociedade do consumo. Revista Pro-Posições, v. 14, n. 3 (42), set-dez. 2003.

FINCO, Daniela. Relações de gênero nas brincadeiras de meninos e meninas na educação infantil. Revista Pro-Posições, v. 14, n. 3 (42), set-dez. 2003.

FREITAS, Daniela Amaral Silva. O discurso da educação escolar nas histórias em quadrinhos do Chico Bento. 2008. 146f. Dissertação (Mestrado em Educação). Universidade Federal de Minas Gerais, Faculdade de Educação. Belo Horizonte, 2008.

GIROUX, Henry A. Memória e pedagogia no maravilhoso mundo da Disney. In: SILVA, Tomaz Tadeu da (Org.). Alienígenas na sala de aula. 10. ed. Petrópolis, RJ: Vozes, 2012.

LEAL, Sandra Maria Cezar. A ênfase higienista da educação e saúde na sala de aula. In: MEYER, Dagmar Estermann; ZEN, Maria Isabel Dalla; XAVIER, Maria Luisa de Freitas (Orgs.). Saúde e sexualidade na escola. Porto Alegre: Mediação, 1998.

LOURO, Guacira Lopes. Gênero, sexualidade e educação: uma perspectiva pósestruturalista. Petrópolis, RJ: Vozes, 1997.

PARAÍSO, Marlucy Alves. Contribuições dos Estudos Culturais para a educação. Presença Pedagógica, v. 10, n. 55, jan./fev. 2004.

PARAÍSO, Marlucy Alves. Currículo e mídia educativa brasileira: poder, saber e subjetivação. Chapecó: Argos, 2007. 
SABAT, Ruth. Pedagogia cultural, gênero e sexualidade. Estudos feministas, v. 1, ano 9, $2^{\circ}$ semestre, 2001, p. 9-21.

SANT'ANNA, Denise Bernuzzi de. Corpo e embelezamento feminino no Brasil. Iberoamericana, v. III, n. 10, 2003, p. 143-151.

SILVA, Maria Carolina da. Infância no currículo de filmes de animação: poder, governo e subjetivação dos/as infantis. Dissertação (Mestrado em Educação). Faculdade de Educação, Universidade Federal de Minas Gerais. Belo Horizonte: UFMG/FaE, 2008. 